\title{
FONOGRAFIA RELIGIOSA AFRO-GAÚCHA: O RITUAL E O GRAVADO NO CONTEXTO DE NOVAS ARTISTICIDADES
}

\section{Leonardo Oliveira de Almeidal}

Resumo: $\mathrm{O}$ presente trabalho tem como objetivo apresentar alguns aspectos relacionados à produçáo fonográfica afro-gaúcha. Busco mostrar que esses fonogramas vêm possibilitando o surgimento de novos repertórios de mediação com o sagrado e o fortalecimento do que chamo de artisticidade religiosa afro-brasileira. Como pano de fundo, argumento que a compreensão da questáo pressupóe a quebra de linearidades entre o terreiro e o estúdio (CD), bem como das hierarquizaçôes unidirecionais daí decorrentes. Em complemento, afirmo que a produção fonográfica afro-gaúcha adere a modelos da indústria musical, recompondo as relações entre o ritual e o gravado a partir de novos parâmetros: o gravado $(\mathrm{CD}$, $\mathrm{mp} 3$, DVD, entre outros) e o ao vivo (o ritual no terreiro como um show, espaço de consolidação de artisticidades).

Palavras-chave: Produção Fonográfica; Artisticidade; Religiōes Afro-Brasileiras.

Abstract: This work aims to present some aspects related to the afro-gaucho's phonographic production. I argue that these phonograms have enabled the emergence of new repertoires of mediation with the sacred and the strengthening of what I call Afro-Brazilian artisticity. As a background, I argue that the understanding of the issue presupposes the breakdown of linearities between the terreiro and the recording studio $(\mathrm{CD})$, as well as the unidirectional hierarchies resulting therefrom. In addition, I affirm that afro-gaucho music production adheres to models of the music industry, recomposing the relationships between ritual and recorded from new parameters: recorded (CD, mp3, DVD, among others) and live (the ritual in the terreiro as a show, place of consolidation of artisticities).

Keywords: Phonographic Production; Artisticity; Afro-Brazilian Religions.

1 Doutorando do Programa de Pós-Graduação em Antropologia Social da Universidade Federal do Rio Grande do Sul (PPGAS - UFRGS).

Contato: leonardoalmeida_cs@yahoo.com.br 


\section{INTRODUÇÃO}

A produção fonográfica afrorreligiosa no Rio Grande do Sul teve seu início provavelmente na década de 1970, com os discos (LP) Saravá Mamãe Oxum (1975), de Wilson Ávila e J. Cicero, e Este é o Nagô do Rio Grande do Sul Vol. 1 (1978) ${ }^{2}$, gravado por Abelardo Pereira. Estes seriam alguns dos pontos iniciais de uma produção fonográfica de caráter comercial que posteriormente viria a reconfigurar o fazer musical afro-gaúcho. Nesse percurso, esses religiosos, em sua maioria pais e mães de santo e alabês ${ }^{3}$, realizaram desde gravaçôes caseiras até gravaçôes que contaram com a parceria de empresas que atuavam também fora do meio religioso, tais como Artes Discos e DEX.

Mais recentemente, por volta das décadas de 1990 e 2000, temos o surgimento de gravadoras especializadas no universo afro-brasileiro, tais como a Atabaque's Records, que lançou tamboreiros prestigiados no meio religioso: Antônio Carlos de Xangô, Jorge Belerum de Oxalá, Chamim de Aganju, Mestre Borel, entre outros ${ }^{4}$. Também é importante citar os estúdios disponíveis nas cidades gaúchas, tal como o Estúdio Brother's de Porto Alegre, que já realizou a gravação de diversos CDs voltados para o público afrorreligioso. Após 2010, temos o surgimento de novos estúdios, como o Estúdio Axé Records, "totalmente voltado para religião" e empresas de mídia afro-brasileiras com atuação mais ampla, responsáveis

2 Braga (2013) situa o lançamento do LP em 1981, o que provavelmente faz referência ao lançamento de uma das partes do trabalho. A partir de 1978, alguns volumes foram lançados em decorrência da impossibilidade de registrar em apenas um LP todas as rezas do ritual do batuque.

3 Pessoas responsáveis pelo canto, toque dos tambores e condução musical do axé e das energias espirituais.

4 Entre os principais trabalhos da Atabaque's Records, foram lançados Atetés ti Axexês ti Eguns, dos alabês Belerun ti Oxalá e Xamim Ti Agadju (2007); Raizes de Cabinda, de Antônio Carlos de Xangô (2008); Cantos à Nação Cabinda, de Xamim Ti Aganju (2009); Shirê de Oyó e Ijeshá, de Mestre Borel de Xangô (2008), entre outros.

5 Descrição presente na página oficial do estúdio no Facebook. 
tanto pela produção dos fonogramas como por sua divulgação e distribuiçãa, além de prestar assessoria de marketing e publicidade para os músicos - este é o caso da produtora Donos da Noite.

Tal como nos estudos de Hirschkind (2006) sobre os sermóes em fitas cassete distribuídas no Cairo e em algumas regiōes do Oriente Médio, os CDs que serão apresentados neste trabalho podem ser situados em um dos diversos momentos do processo de latência dessas mídias, reaparecendo em contextos e momentos distintos e contribuindo para a transformação de sentidos (sentir) e hábitos de percepção. Se desde a década de 1970 observamos a presença de fonogramas voltados para o público religioso afro-gaúcho, considero que esses CDs (e outro formatos, tais como LPs e fitas cassete), em suas diversas épocas, ajudam a contar a história das religióes afro-brasileiras no Rio Grande do Sul precisamente pelas transformaçóes nos regimes de mediação que propuseram e fizeram parte.

Nos últimos anos a produção fonográfica afro-gaúcha vem sendo influenciada por pelo menos dois fatores que muito interessam aos argumentos que serão apresentados neste texto. Primeiro, as reconfiguraçóes do campo afro -religioso gaúcho, marcado por um acelerado crescimento da popularidade da quimbanda a partir da década de 1980, movimento já evidenciado por alguns autores (Corrêa, 2006; Oro, 2008; 2012; 2014), além do fato de que a maioria dos terreiros nesta região do país afirma se dedicar (em momentos e, muitas vezes, em espaços distintos) às três modalidades rituais presentes no estado - batuque, umbanda e quimbanda (Corrêa, 2006; Braga, 1998; Oro, 2008; 2012). Vale ressaltar também o que diversos religiosos chamam de "o desaparecimento da umbanda", referindo-se ao número cada vez menor de terreiros que afirmam praticar rituais de umbanda ou à frequência com que esses rituais são realizados. Como resultado, são os $\mathrm{CD}$ s de quimbanda os que mais ganharam destaque nos últimos dez anos, seguidos dos CDs de batuque e, em menor quantidade, os CDs de umbanda.

Dessa forma, somos levados ao segundo fator que vem influenciando na produção fonográfica afro-gaúcha. Segundo Alberto Flores, dono de uma das maiores empresas de mídia voltadas para o público afrorreligioso no Rio 
Grande do Sul, o Grande Axé , há uma curiosa e diferenciada relação entre tipos de divindades (entidades e orixás) e as novas mídias. Por exemplo, conta Alberto sobre a produção de imagens (fotos e vídeos, transmissōes ao vivo no Facebook etc.), que as entidades da umbanda, principalmente os caboclos, não demonstram interesse pelo registro de sua imagem. Os orixás, por sua vez, segundo as tradiçôes do batuque, não podem ser filmados ou fotografados após sua chegada ao terreiro. Assim, qualquer registro visual no ambiente ritualístico do batuque só pode ser feito antes da chegada dos orixás ou após sua saída. Ainda assim não são poucos os registros audiovisuais realizados nesses rituais, ganhando destaque, por exemplo, a decoração e as mesas de comida em detrimento da performance dos orixás incorporados, ou ainda ao explorar ângulos que capturem momentos do ritual sem que os orixás sejam registrados. A quimbanda, por outro lado, é a modalidade ritual que mais se aproveitou dos usos das novas mídias, pois, comenta Alberto, "o exu gosta de aparecer".

Na mesma linha, Rafael Luz, fotógrafo e dono da Planeta África, empresa que também realiza o registro de imagens em terreiros e eventos afrorreligiosos, comenta: "Anos luz na frente o exu. O santo a gente nem fotografa e o caboclo não reage tanto a isso, nem nos vê na festa. As outras entidades da umbanda, preto velho, erê, cosme, entra junto, náo dão bola. Já o exu não, o exu na quimbanda já interage até de foto, nos pedem pra tirar foto. O que interage é o exu, disparado, não tem nem como discutir"”.

Dito isso, e a partir da pesquisa que venho realizando junto às produtoras e empresas de mídia afro-gaúchas, é possível afirmar que, nos últimos anos, o crescimento da quimbanda e do uso das novas mídias possuem uma relação complementar. Este fato muito contribui para as controvérsias em

6 Fundado em 2008, o Jornal Grande Axé é hoje uma das principais empresas de mídia religiosa no Rio Grande do Sul, comumente contratada para realizar o registro fotográfico de rituais e eventos, além da edição de um jornal com conteúdos também voltados para o público afrorreligioso.

7 Entrevista realizada em agosto de 2017. 
torno da chamada "espetacularização da religiaao", tema que rende diversos debates entre lideranças religiosas e que já foi abordado em trabalhos como de Oro (2014). Essas consideraçóes são de grande importância para os argumentos que serão apresentados neste trabalho, sobretudo pelo fato de que os CDs de quimbanda terão maior destaque.

Em suas contribuiçôes ao estudo da relação entre religiaáo, mídia e mediação, Birgit Meyer (2011, p. 28) busca situar a adoção de novas midias em um quadro histórico de práticas duradouras de mediação religiosa que se transformam, através do tempo, por meio da negociação com as novas tecnologias disponíveis. Dessa forma, mídias adquirem um sentido mais amplo, que não se restringem apenas aos recursos tecnológicos, e que nos possibilitam refletir sobre a suposta "novidade" desses recursos. Dito de outra forma, na perspectiva de Meyer as novas tecnologias não podem ser compreendidas sem considerarmos outros mediadores e práticas de mediação de longa data, colocando em xeque a suposta novidade dessas tecnologias. Falar em "práticas duradouras de mediaçáo religiosa que se transformam", portanto, torna-se ainda mais pertinente quando o que está no centro da análise é um recurso há muito presente no repertório religioso afro-gaúcho, o fonograma, agora combinados com a atuação de novos recursos tecnológicos e com o que pretendo chamar de artisticidade afro-gaúcha.

Em resumo, dedico este trabalho à apresentação de alguns aspectos relacionados à produção de CDs de quimbanda no Rio Grande do Sul. Esses CDs contêm pontos, músicas que narram a história e os feitos de entidades espirituais e que possuem papel de extrema importância no principal ritual público de culto aos exus: a curimba. Para tanto, tratarei inicialmente do que chamo de artisticidade afro-brasileira. Em seguida, afirmo que a compreensão

8 A expressão artisticidade é comumente utilizada em diferentes áreas, tais como arte, moda, música e etnomusicologia, literatura, entre outros, adquirindo sentidos diversos. Utilizarei a artisticidade como uma expressão que indica níveis de proximidade com elementos advindos do universo musical e artístico e que, a partir de ênfases distintas, inspiram a performance e o uso das mídias eletrônicas e digitais por parte dos produtores e receptores de fonogramas.

Debates do NER, Porto Alegre, Ano i9, N. 33, P. i 97-234, Jan./Jul. 20 i 8 
da atuação dos fonogramas pressupóe a quebra de linearidades entre o terreiro e o estúdio, buscando evidenciar as múltiplas direçôes e as variaçôes nos regimes de mediação protagonizados pelos CDs em questão. Nesse processo, as concepçôes sobre o terreiro e o estúdio são transformadas: por um lado, o gravado (CD, mp3, DVD, entre outros) e, por outro, o a vivo (o ritual no terreiro como um show, momento de expressão e consolidação de artisticidades). No tópico seguinte, trago a noção de circuitos autônomos com o intuito de apresentar certas especificidades da produçáo fonográfica afro-gaúcha. Por fim, retomo as discussóes apresentadas até entâo tendo como base alguns $\mathrm{CDs}$ de quimbanda lançados por dois alabês de grande prestígio entre os quimbandeiros do Rio Grande do Sul: Étto Mendes, o alabê romântico, e Vagner D'Agandjú, o alabê "de Lei".

O processo de pesquisa que embasa este texto foi realizado junto aos alabês e empresas de mídia que atuam no Rio Grande do Sul. Tive a oportunidade de acompanhar esses atores tanto em rituais realizados nos terreiros como em processos de gravação em estúdio. Sobre este último, ao longo do ano de 2016, pude acompanhar a gravaçáo de seis CDs de quimbanda, tendo inclusive a oportunidade de participar, em alguns casos, das equipes de produção responsáveis pela manipulação de equipamentos de áudio e vídeo.

\section{ARTISTICIDADE AFRO-BRASILEIRA}

O crescimento da quimbanda no Rio Grande do Sul, juntamente com a intensificaçáo dos usos das novas mídias, apontam para o surgimento e fortalecimento do que pretendo chamar de artisticidade afro-brasileira. Esta, porém, náo deve ser confundida com o prestígio possuído pelos autores de fonogramas desde o final da década de 1970. Nesse contexto, é possível afirmar que tamboreiros mais antigos, tais como Antônio Carlos de Xangô, Mestre Borel, Chamim de Aganju, Jorge Belerum, entre outros, gozaram

9 Trata-se de alguns resultados de pesquisa de doutoramento, vinculada ao Programa de Antropologia Social da Universidade Federal do Rio Grande do Sul. 
e ainda gozam de grande prestígio no meio religioso, sem que necessariamente tenham relação com o que venho chamando de nova artisticidade afro-gaúcha. Considero que tal artisticidade também pode ser compreendida como um desdobramento do que Braga (2013) já evidenciava sobre o intenso processo de profissionalização dos tamboreiros gaúchos. O novo fato é que a artisticidade ganhou popularidade e agora pode gerar prestígio e com isso possibilitar o fortalecimento do poder mágico-religioso de pessoas e exus.

Nos casos que pretendo analisar neste trabalho, a relação entre religião e artisticidade expressa-se quando os alabês, os principais produtores de fonogramas no Rio Grande do Sul, passam a utilizar palavras como "artista", "fấs", "presença de palco", "carreira", "trabalho autoral”, "show", "ao vivo", entre outras expressóes que até pouco tempo pareciam pertencer apenas a outros universos, fora do contexto afrorreligioso/ritualístico ${ }^{10}$. Esses alabês também utilizam estéticas observadas na atuação de cantores de pagode, buscam criar sua identidade artística (roupas personalizadas, adereços, performances específicas, nomes originais, logomarcas e slogans), associam-se com empresas de mídia e marketing voltadas exclusivamente para o público afrorreligioso e gravam CDs de quimbanda ao vivo, muitas vezes considerando o próprio ritual do terreiro como um show ${ }^{11}$.

Felipe Paiva, criador da Donos da Noite, uma das produtoras que realiza trabalhos de mídia e marketing voltados para o público afrorreligioso, comenta

${ }^{10}$ Utilizo o termo ritualístico para distinguir a produção fonográfica em questão de outras produçóes que possuem forte relaçáo com o universo afro-brasileiro, mas que não apresentam uma intensa participação no cotidiano ritualístico do terreiro.

11 Ao longo do processo de pesquisa, a relação entre a performance no terreiro e o show me foi apresentada de diversas formas, a partir de diferentes intensidades, ora evidenciando clara proximidade entre o ritual e os shows de música secular, expondo como os modelos performáticos do show são postos em prática durante os rituais, ora em tom de brincadeira, muitas vezes utilizando a jocosidade como recurso para amenizar as possíveis controvérsias resultantes do uso de uma expressão que ainda não encontra total aceitação no campo afrorreligioso. 
sobre o início de sua atuação empresarial, bem como suas primeiras impressôes sobre o mercado que, na época (por volta de 2010), estava emergindo:

Roupa, uniforme, camiseta personalizada, barba bem feita, uma boa apresentação, os guris [alabês] começaram a estudar música, voz, canto, toque. Enfim, foi uma evolução, profissionalizamos isso mesmo, assim, profissional. E o preço, claro, virou profissional também. E eu vi que eu comecei a criar uma identidade pra cada um. A partir disso o Alabê virou um artista, um músico, uma pessoa conceituada, entâo a gente consegue fundir um pouco da criação de arte, duma coisa mais moderna, mas dentro do trabalho não perde fundamento [fundamento religioso], entendeu? [...] eu vi que tinha um mercado inexplorado e dava pra sobreviver disso. E foi assim que eu fundei a Donos da Noite. (Entrevista com Felipe Paiva, abr. 2016).

Em outro momento da mesma entrevista, Felipe comenta sobre a mudança de status dos alabês ao aproximarem-se das mídias, inclusive após a gravação de um CD: "Quando os caras gravaram um CD, muda, as pessoas têm uma visão diferente, ele é um artista. CD é uma referência pra pessoa virar artista, é um encanto".

Tais movimentos não passam despercebidos aos olhos dos tamboreiros mais antigos, que comumente criticam tais práticas, chamando-os pejorativamente de alabês popstars, e reivindicam o uso do termo tamboreiro, em referência aos responsáveis pelo canto e toque dos tambores antes do surgimento dos alabês ${ }^{12}$. Também é provável que o uso da expressão artisticidade venha a gerar controvérsias ou tenha uma má recepção entre alguns desses tamboreiros, apesar da palavra artista ter sido comumente adotada nos últimos anos.

Para início de discussão, considero que a relação entre religião e artisticidade pressupóe, portanto, a influência do que se convencionou chamar de

12 Termo utilizado recentemente, sobretudo nos últimos dez anos, com frequência relacionado às novas geraçóes de tocadores de tambor, aos usos das novas mídias, ao surgimento dos concursos de alabês e de um caráter artístico da função.

Debates do NER, Porto Alegre, ano i9, N. 33, P. I97-234, JAn./Jul. 20 I 8 
popular culture (Forbes; Mahan, 2017; Lyden; Mazur, 2015; Mazur; Mccarthy, 2001; Lynch, 2007) na prática religiosa. Além deste, outros termos são comumente utilizados por autores que abordam o tema: music business, cultura pop, mercado musical, música secular. Forma-se um espectro de variaçóes possíveis, em um campo que faz emergir expressóes como artistas religiosos ou religiosos artistas, comumente responsáveis pelo surgimento de debates e controvérsias quanto aos seus possíveis e diversos significados e atuaçóes.

Howard e Streck (1996; 2015), ao criarem certas categorias de classificaçáo para o que se convencionou chamar de CCM (Contemporary Christian Music), falam sobre os músicos transformacionais, fazendo referência aos níveis de relação entre religião e cultura. Os autores afirmam: "The transformational musicians tend to think of thenselves as 'artists' rather than as 'ministers"' (Howard; Streck, 1996, p. 47). Howard e Streck colocam em discussão a complexa relação entre artisticidade e ministério (função religiosa), fazendo emergir questôes sobre as condiçóes e possibilidades de existência e atuação de ministros artistas sem que haja relação de exclusão entre essas duas características. Como se constroem ministros artistas? Quais controvérsias sáo geradas a partir da aproximaçáo entre religiáo e cultura (aqui entendida como cultura pop, música popular, música não religiosa, entre outras expressóes)?

Podemos dizer que o caso da cantora norte-americana Amy Grant está entre os principais exemplos de como a relação entre a função religiosa (ministério) e a artisticidade pode ser discutida, gerando controvérsias e reajustando o campo religioso e sua relação com o chamado music business, tema já bem explorado por Romanowski (2005) e Howard e Streck (1996; 2015). No caso brasileiro, a música gospel do Diante do Trono, Thales Roberto, Oficina G3, entre outros, já foi objeto de estudos sobre a relação entre religiáo e marketing, mídia e o mercado musical, também apontando para essas novas reconfiguraçóes e relaçóes religião/cultura ${ }^{13}$. Também poderíamos citar o caso dos padres cantores (Carranza, 2011; Souza, 2005), das gravadoras cristás (Sergl; Vicente, 2008) e artistas que se utilizam de

${ }^{13}$ Ver Rosas (2013). 
ritmos musicais considerados por muitos como seculares (Bonfim, 2015) ou até demoníacos (Jungblut, 2007). Como pano de fundo ou como temática central, comumente são discutidas as controvérsias em torno dessa artisticidade emergente, da produção musical em parceria com as majors e do uso de estratégias e estéticas advindas do mercado musical secular. Mas é importante ressaltar que a artisticidade não se constrói apenas a partir de elementos advindos "de fora” do campo religioso, pois as geraçôes já consolidadas de ministros artistas também são importantes fornecedores de modelos performáticos, estratégicos e estéticos.

Artisticidade, por fim, tal como pretendo apresentar neste trabalho, não pressupóe a renúncia da atuação ministerial (função religiosa) ${ }^{14}$ ou ainda uma atuação que dependa necessariamente da autodeclaração artística ("eu sou um artista") ${ }^{15}$. Trata-se, por outro lado, de uma expressão que indica proximidade com elementos artísticos, melhor compreendidos no campo da performance e quando nos debruçamos sobre as particularidades do campo religioso em questão. O sufixo -dade, tendo como origem o sufixo latino -tati, forma substantivos abstratos que designam quantidade, qualidade, modo de ser, estado, propriedade. Dessa forma, a expressão artisticidade pode ser utilizada como medida abstrata, tal como na palavra plasticidade (maleabilidade de determinado elemento, pessoa ou coisa). Nesse caso, a artisticidade permite-nos falar em graus de incorporação ou presença de elementos artísticos.

Obviamente os casos das religiôes cristãs saltam aos olhos quando estas questôes são discutidas. Mas como se configura o caso das religiōes afro -brasileiras? No contexto brasileiro, não devemos esquecer que o espectro da artisticidade, sujeito a intensas controvérsias, entra em questão de forma mais evidente quando a música afro-brasileira ultrapassa os muros dos terreiros, quando vai "conta pra todo canto" (Amaral; Silva, 2006). Como ressaltaram

${ }^{14}$ Utilizo a palavra "ministerial” como termo genérico que faz referência a uma função ou atuação religiosa.

15 Para diversos alabês entrevistados, sua profissão pode ser claramente definida como uma atuação artística. 
Sandroni (2001) e Moura (1983) sobre a história do samba, os terreiros eram ao mesmo tempo local de culto, moradia e espaço de lazer, fazendo emergir diversos cantores e instrumentistas que viriam a se tornar referências do samba e de outros estilos musicais que têm as religióes afro-brasileiras como tema de grande importância em suas composiçôes e performances.

Mas há diferentes formas de performatização da artisticidade afro-brasileira. No caso da cantora Clara Nunes, por exemplo, por volta do final da década de 1960 e início da década de 1970, ela inicia "um processo de construção de uma imagem artística que associava a cantora às tradiçóes culturais afro-brasileiras" (Bakke, 2007, p. 87). A música com temas afrorreligiosos ultrapassa seus usos ritualísticos e adentra o campo da cultura e do entretenimento, podendo também alcançar um público não religioso.

Os casos do ogã Tião Casemiro e pai Élcio de Oxalá, e de uma geração mais recente de ogãs, como Léo Batuke e Cristiano Umbanda, que adquiriram reconhecimento em diversas regióes do país por suas composiçóes ${ }^{16}$, aproximam-se ainda mais do caso gaúcho, pois permite que pensemos na artisticidade fortemente vinculada a uma função ritualística, a de ogã ou pai de santo. Dessa forma, é possível afirmar que a artisticidade afro-gaúcha recebe influências tanto do universo musical secular (cantores de pagode ou música sertaneja), quanto dos cantores e das cantoras que atuam dentro do campo afro-brasileiro, seja a partir de uma atuação que atinge também um público não religioso ${ }^{17}$, seja uma atuação voltada para uma função ritualística, tal como a de ogã/alabê.

Acredito que esses arranjos devem ser compreendidos considerando-se as ontologias próprias do universo afrorreligioso, tema que será discutido de forma introdutória neste trabalho. Entre as principais características do

16 Vale mencionar o importante trabalho escrito por Licia Souza (2016) sobre a música umbandista e a atuação de ogãs a partir das mediações além do terreiro.

17 Braga (2013, p. 221) menciona diversos casos de atuação dos tamboreiros gaúchos no samba e também como cantores e compositores, como músicos profissionais na noite gaúcha, como bailarinos e escritores de teatro.

Debates do NER, Porto Alegre, Ano i9, N. 33, P. i 97-234, Jan./Jul. 20 i 8 
caso afro-gaúcho, já citada anteriormente, é possível destacar a possibilidade de consolidação do poder mágico-religioso através do fortalecimento da artisticidade. Dessa forma, a intensa presença nas redes sociais, os diversos CDs gravados, diversos fầs, uso de equipamentos de som, a presença de palco e a desenvoltura no uso do microfone e as roupas que compóem sua identidade conferem maior poder mágico à prática desses alabês. Envoltos em sua artisticidade afrorreligiosa, transformam a realidade, possibilitam a performance dos exus cultuados no terreiro, atiçam emoçóes.

Outra característica marcante do caso gaúcho é o surgimento de empresas de mídia e marketing voltadas para o público afrorreligioso, muitas delas criadas por alabês. Esse é o caso da GDC Eventos, formada pelo grupo de alabês Guardióes da Calunga; da Visual Axé, criada pelo alabê Felipe de Oxalá e sua equipe, a Família de Ouro; da Planeta África, criada por Rafael Luz; e ainda da produtora Donos da Noite, que esteve à frente da produçáo de alguns dos CDs de quimbanda que serão apresentados neste trabalho. Diversas dessas empresas oferecem equipamentos de som e de luz, estratégias de publicidade e marketing, estrutura de filmagem e fotografia e, no caso da Visual Axé, filmagens aéreas com auxílio de drones ${ }^{18}$.

Como afirma Vagner D’Agandjú ${ }^{19}$, um dos alabês que seráo apresentados logo mais, esta associação dos alabês com as novas mídias, somada ao seu protagonismo na condução dos rituais, vem tornando-se um atrativo para os pais e mães de santo contratantes. Antes da realização da festa/ritual, os líderes religiosos podem dividir com os alabês os trabalhos de divulgação e publicidade, fato que se estende também para o momento ritualístico a partir do que comumente tem sido chamado de "cobertura de mídia". Dessa forma, alabês com uma boa "cobertura de mídia" têm maiores chances de serem contratados. Nesse ponto, não devemos deixar de mencionar que o uso intenso das novas mídias também se adequa à personalidade de diversas

${ }^{18}$ Entre as empresas atuantes no Rio Grande do Sul, também podemos citar: Odum, Kizomba, Afro-Mídia, Grande Axé, Império Mídia, entre outras.

${ }^{19}$ Entrevista realizada em dezembro de 2016. 
linhagens de exus que, como dito anteriormente, "gostam de aparecer". A presença da mídia e da artisticidade desses alabês, portanto, vêm garantindo o espetáculo que os exus desejam.

\section{MÚLTIPLOS MOVIMENTOS: O AO VIVO E O GRAVADO NAS RELIGIÓES AFRO-GAÚCHAS}

Gostaria de iniciar este tópico com um dos textos disponíveis no encarte do CD Yle Omolu Oxum: Cantigas e toques para os orixás, lançado em 2004 como um dos volumes da Coleçáo Documentos Sonoros do Museu Nacional/ UFRJ. O CD teve como principal objetivo realizar a gravação de parte do repertório de cantigas e toques dedicados aos orixás, considerados patrimônio do Ilê Omolu Oxum, tradicional casa de candomblé do Rio de Janeiro.

No tópico Como foi feito este $C D$, presente no encarte ilustrado, um dos autores escreve:

Qualquer disco de candomblé, por melhor que seja, está destinado a ser apenas um pálido reflexo da exuberância e beleza de uma noite de festa no terreiro. Tentar captar em disco a complexidade e riqueza musical do candomblé é uma tarefa difícil em que várias escolhas têm que ser feitas. De fato, toda reprodução fonográfica de um evento musical envolve escolhas: que repertório gravar, como colocar os microfones, como equalizar as gravações...

Chamo a atenção para a expressão "pálido reflexo", logo na primeira frase do trecho, e que faz oposiçáo à "exuberância e beleza de uma noite de festa no terreiro". Há claramente uma comparação entre dois universos distintos, o do ritual e o do CD gravado (e também do processo de gravação). O CD é apresentado como um pálido reflexo do ritual, uma mídia que, apesar de todos os esforços, "por melhor que seja", nunca alcançará a exuberância e beleza de uma noite de festa no terreiro. Evidencia-se o que se perde quando a música se 
desloca "do terreiro para o estúdio" (Vasconcelos, 2011) 20. Percebemos aqui um segundo aspecto: a hierarquizaçáo dos modelos. No caso em questão, é o ritual que fornece os modelos necessários ao processo de gravação, sendo preciso mobilizar diversos recursos para minimizar desencontros.

Fazendo referência ao processo de gravação, Edmundo Pereira (2016, p. 229), que participou intensamente do processo de produção do CD Yle Omolu Oxum, comenta que "mesmo sendo música 'fora do contexto', não podia ser executada de qualquer maneira". Daí resultam as estratégias utilizadas durante a gravação e que visam evitar certos problemas de correspondência entre o ritual e o gravado, bem como minimizar o teor de "pálido reflexo" que o $\mathrm{CD}$ poderia adquirir. Considera-se inevitável que o novo mediador imponha suas próprias lógicas, sendo preciso lançar mão de intensas negociaçôes que levem em conta e minimizem a perda de elementos indispensáveis e que têm como referência a vivência no terreiro. Dessa forma, os grupos religiosos veem-se diante da necessidade de classificar, selecionar, criar e até mesmo hierarquizar certas características do ritual quando um processo de gravação está em curso, dando a devida atenção aos timbres, volumes, toques no tambor, vozes, entre outros. Em complemento, a atenção dada a certos preceitos religiosos durante o processo de gravaçáo, bem afirmam Pereira e Pacheco (2004), nos leva a relativizar a distinção entre 'situação de gravação' e 'situação ritual'.

Imediatamente o caso nos faz lembrar as famosas afirmaçôes de Walter Benjamin sobre a perda da aura na era da reprodutibilidade técnica, em que "à mais perfeita reprodução falta sempre algo: o hic et nunc da obra de arte, a unidade de sua presença no próprio local onde se encontra" (Benjamin, 1969, p. 13). E se, tal como afirma Benjamim, a reproduçáo emancipa a obra de arte do ritual, também podemos observar novamente o estabelecimento de hierarquias entre o ritual e o gravado, estando este último submetido ao primeiro, mesmo que sejamos convidados a relativizar a distinção entre

${ }^{20}$ Destaco a ideia de deslocamento contida no título do texto de Vasconcelos (2011): "Dos terreiros para o estúdio".

Debates do NER, Porto Alegre, ano i9, N. 33, P. I97-234, JAn./Jul. 20 I 8 
"situação gravada" e "situação ritual". Nesse contexto, proponho que a compreensão do jogo de hierarquias e referências entre o ritual e o gravado pode render boas reflexóes sobre as dinâmicas recentes no campo afrorreligioso gaúcho, principalmente se pensarmos a partir de outros caminhos que não buscam evidenciar apenas a submissão do gravado ao ritual. Daí decorre a possibilidade de falar, por exemplo, em outros deslocamentos, movimentos que vão dos estúdios (e dos CDs) para os terreiros, ou a partir de outras reflexôes que não impliquem necessariamente em deslocamentos lineares e que envolvam apenas esses dois universos.

Como mostrarei ao longo deste trabalho, o caso gaúcho evidencia tanto os cuidados religiosos com o processo de gravação (cuidados que, em muitos casos, tiveram sua origem nos modelos ritualísticos do terreiro), como certa independência, possibilitando à mídia criar novas estéticas (muitas vezes inspiradas na produção musical secular, tais como CDs e DVDs de pagode, sertanejo, entre outros) e novas práticas de mediação com o sagrado, que em diversos casos se tornam o substrato das práticas que serão vivenciadas no terreiro. Quero, portanto, analisar como o CD adquire sua autonomia e de que forma são construídos elementos que não tem por intenção inicial ser uma reprodução do momento ritual supostamente "original", mas como espaço de transformação, criação e sugestão de formas de mediação com o sagrado. O sucesso e a aceitação dessas sugestôes irão conferir ao seu criador prestígio e poder mágico-religioso.

Ao discutirmos a materialidade desses CDs, devemos considerar os complexos regimes de circulação, de variações de biografias (Kopytoff, 2009), usos e sentidos a que são submetidos os objetos em movimento. Ao ocuparem os diversos espaços, desde o CD player de um automóvel até uma foto publicada no Facebook, os CDs produzem referências, mediam e produzem modelos de mediação. Talvez o rompimento dessas linearidades ${ }^{21}$

${ }^{21} \mathrm{O}$ rompimento dessas linearidades se daria em dois níveis extremamente imbricados: um religioso e outro analítico. Tanto os adeptos das religióes afro-brasileiras passaram a ampliar os espaços de atuação dos fonogramas, quebrando linearidades entre o ritual

Debates do NER, Porto Alegre, Ano i9, N. 33, P. i 97-234, Jan./Jul. 20 i 8 
(do terreiro ao estúdio/do estúdio ao terreiro) seja uma das principais motivaçóes para sua grande popularidade, sobretudo nos últimos cinco anos. Ao longo do processo de pesquisa, pude presenciar o uso desses CDs e mp3 durante o preparo dos alimentos na cozinha dos terreiros, nos minutos que antecediam o início dos rituais, nos cursos para novos alabês, nos pedidos de autógrafo feitos pelos fãs, em transmissōes ao vivo no Facebook, durante o preparo do churrasco em um domingo de lazer, ou ainda quando, no transporte público, os pontos de exu embalavam o trajeto entre a casa e o trabalho, entre outros momentos.

Mas a discussão sobre o ritual e o gravado também nos aponta para outra questão, que igualmente pode ser compreendida como uma reestruturação do campo afro-gaúcho. Tal como venho apresentando a partir de diferentes perspectivas, nos últimos anos, diversos alabês vêm incorporando estéticas, estratégias e performances do universo pop, do pagode, do music business, entre outros. Um desses pontos de aproximação é o estabelecimento de relaçóes entre o ritual de quimbanda e um show, sendo este referido muitas vezes como o ao vivo, em complemento ao gravado (fonogramas e estúdios, DVDs, videoclipes, entre outros). Se, por um lado, há a flexibilizaçáo das linearidades e do estabelecimento de hierarquizaçóes entre o ritual e o gravado, por outro, as religióes afro-gaúchas vêm reconfigurando a relação entre os dois universos a partir da influência do mercado musical. Como afirma Étto Mendes (alabê que será apresentado mais adiante), quando um pai de santo o contrata para tocar tambor em seu terreiro, "ele quer aquilo que ele ouviu no CD" e, mais recentemente, aquilo que ele viu e ouviu no DVD. O terreiro transforma-se no momento do ao vivo, do show.

e o gravado, como o estabelecimento de hierarquias entre ritual e gravado deixa de ser o único caminho analítico possível. 


\section{CIRCUITOS AUTÔNOMOS DE PRODUÇÃO FONOGRÁFICA AFRO-GAÚCHA}

Como aponta Marchi (2012), a indústria fonográfica brasileira vivenciou um processo de descentralização a partir da década de 1990. Tal descentralização esteve marcada pela terceirização das etapas do processo fonográfico, caracterizada pela associação com gravadoras menores ou chamadas independentes, e pelo uso de novas tecnologias, sendo essas medidas parte do processo de reestruturação diante dos novos desafios, sobretudo após a intensificação da pirataria e o surgimento e popularização das tecnologias digitais. Como resultado, abriu-se espaço para o surgimento de gravadoras e produtores independentes, ou "nova produção independente" (Marchi, 2012), considerada uma das principais inovaçóes no período e que até os dias atuais vem diversificando-se e adquirindo novos contornos ${ }^{22}$.

Por outro lado, Herschmann (2011) ressalta a dificuldade de se identificar uma linha divisória entre o que se convencionou chamar mainstream e a música independente. Esta última expressão vem sendo utilizada para fazer referência a uma grande variação de situaçóes, tanto a pequenas gravadoras como às bandas autônomas, responsáveis pelo seu próprio processo de produção e distribuição de fonogramas. Prefiro, portanto, utilizar aqui duas digressóes teóricas. Em primeiro lugar, a de Leonardo Marchi (2012) sobre os "artistas autônomos", responsáveis pela gravação, divulgação e venda de seus fonogramas, e que também vem evidenciando certa institucionalização de uma atuação empresarial, elementos que contribuem para o argumento da artisticidade afro-brasileira. E, em segundo, o de "circuitos autônomos" (Vicente, 2002; 2006), provavelmente o que mais pode auxiliar nas discussóes que se seguem.

${ }^{22}$ É importante ressaltar que a chamada música independente teve início no Brasil a partir da década de 1970 (Marchi, 2012; Herschmann, 2011). Dessa forma, a expressão "nova música independente" utilizada por Marchi (2012) faz referência à nova etapa vivenciada a partir da década de 1990 . 
Sobre a ideia de "circuitos autônomos", Eduardo Vicente (2006, p. 11) designa um tipo de produção independente em que as fortes vinculaçôes identitárias (comportamentais, geográficas, étnicas, religiosas etc.) e o acesso às tecnologias permitem a formação de uma rede de produção e distribuição cultural fora do âmbito das grandes gravadoras ou das redes nacionais de mídia. $\mathrm{O}$ autor nos apresenta três condiçóes principais de existência desses circuitos: primeiro, a possibilidade de pulverização da produção musical e reduçáo de seus custos, propiciadas pelas tecnologias digitais, que viabilizaram não só a criação de estúdios locais, como também o retorno do investimento a partir da venda de quantidades cada vez menores de discos. Segundo, o surgimento de redes locais de comunicaçáo, como pequenas emissoras de TV, rádios comunitárias, piratas, etc., que tendem a incorporar a produção dos artistas locais à sua programação, ao contrário do que ocorre com as grandes redes de mídia. Por fim, a possibilidade da intercomunicaçáo global (principalmente pela Internet) que permite a ampliaçáo do mercado potencial dessa produção $0^{23}$.

No caso das religiôes afro-gaúchas, já considerando a existência de linguagens comuns presentes no campo religioso, acredito que o surgimento ou adoçáo de hábitos relacionados a uma atuaçáo empresarial, como afirma Leonardo Marchi sobre os "artistas autônomos", e o surgimento de parcerias com produtoras afrorreligiosas contribuem para a composição desses circuitos. Entre as principais características dos circuitos autônomos afro-brasileiros de produção e comercialização de fonogramas, poderíamos citar também a venda e divulgação de CDs com o auxílio das redes sociais, a possibilidade de venda em rituais de quimbanda ${ }^{24}$, a contratação de motoboys para a

${ }^{23} \mathrm{O}$ autor nos apresenta como exemplo a produção de fonogramas de cunho religioso (católico e evangélico) e, entre outros, os fonogramas vinculados aos Centros de Tradições Gaúchas (CTGs).

${ }^{24}$ Prática cada vez mais comum é a venda de CDs após os rituais de quimbanda, ainda no espaço do terreiro. Os alabês podem comercializar seus CDs no calor do momento, logo após a festa, além de conversar com seus fấs e admiradores, tirar fotos.

Debates do NER, Porto Alegre, ano i9, N. 33, P. I97-234, Jan./Jul. 20 i 8 
entrega dos produtos aos compradores, a divulgação em programas de TV ou transmitidos pelas redes sociais ${ }^{25}$, parceria com as floras (lojas de artigos religiosos), bem como a possibilidade de o terreiro se configurar como espaço de consolidação de artisticidades.

\section{O QUE FAZEM OS CDS DE QUIMBANDA}

Além de propor e transformar formas de mediação com o sagrado, os CDs em questão contribuem com a formação e consolidação do que chamei de artisticidade afro-brasileira desses alabês. Para melhor esclarecer tais questôes, apresento o CD Luz para as Almas, da equipe de alabês Mestres da Magia. Trata-se de um CD composto exclusivamente por pontos autorais e inéditos, escritos por Felipe Paiva (produtor) e os alabês Étto Mendes e Thiago Silva. A equipe foi formada em 2012, tendo encerrado suas atividades em meados de 2014. Apesar disso, seus ex-integrantes permanecem atuando como alabês e até hoje gozam do prestígio adquirido após o lançamento de seu primeiro e único $C D$.

Lançado em 2013, o Luz para as Almas é considerado até hoje um dos CDs de quimbanda de maior repercussão em Porto Alegre. Pelo menos dois fatores podem ser apontados como motivos de sua popularidade: primeiro, o prestígio de ambos os alabês na comunidade afro-gaúcha, reafirmado pelos aspectos inovadores da obra em questáo. Nesse sentido, considero que o Luz para as Almas inaugura uma nova etapa da artisticidade afro-gaúcha, em especial pela parceria com uma produtora voltada para o mercado religioso afro-brasileiro, a Donos da Noite, que possibilitou não apenas a gravação e

${ }^{25}$ Após o surgimento da live (transmissão ao vivo), disponível aos usuários do Facebook, e de diversos programas voltados para o público afrorreligioso, essas redes de divulgaçáo passaram a se fortalecer ainda mais. Exemplo disso são os programas Casa de Santo, apresentado por mãe Viviane de Yansã e pai Mario de Oxalá; o DeBate Tambor, apresentado por Felipe Paiva; o Ritos, Cantos e Magia, apresentado por mãe Ana de Oyá e pai Neco de Oxalá; o programa Kizomba, apresentado por Israel Ávila, entre outros. 
distribuição do $\mathrm{CD}$, mas também a chamada "cobertura de mídia" atrelada a estratégias de marketing e publicidade.

Como exemplo de algumas dessas inovações, comecemos pela sessão de fotos feitas pelo fotógrafo gaúcho Marcelo Brandão, meses antes do lançamento do CD Luz para as Almas, e que nos auxiliam na compreensão de como o trabalho de mídia e marketing contribuíram na composição da artisticidade desses alabês. As imagens apresentam os alabês Étto Mendes e Thiago Silva vestidos de terno italiano no cemitério da Santa Casa de Porto Alegre, sugerindo novas estéticas para os alabês de curimba.

Figura 1

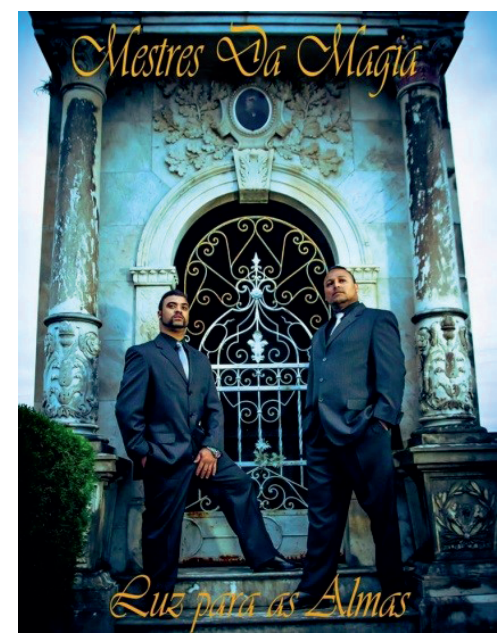

Fonte: Produtora Donos da Noite. Foto: Marcelo Brandão (2013).

Novos ângulos, novas estéticas e narrativas foram utilizadas e, como afirma Étto Mendes em entrevista, tinham o objetivo de fazer:

[...] um troço diferente. 'Vamo alugar roupa... Vamo fazer alguma coisa que ninguém fez ainda'. E a gente conseguiu, graças a deus, montou os Mestres da Magia. E aí a gente foi pro cemitério. 'Vamo fazer uma coisa diferente, que ninguém fez'. A gente gastou R \$ 10.250,00 pra fazer o CD, alugamos o paletó pra fazer as fotos. (Entrevista com Étto Mendes, jul. 2016). 
Após o ensaio fotográfico, as imagens passaram a ser divulgadas em diversas mídias que vinculavam o nome da equipe. Também foi criada a logomarca oficial dos Mestres da Magia, impressa em camisas personalizadas, banners que eram postos por trás dos alabês durante os rituais de quimbanda e nos vídeos postados no Youtube, pôsteres de divulgação, entre outros lugares. $\mathrm{O}$ canal da equipe no Youtube também passou a contar com vídeos publicados periodicamente, diversos deles produzidos pela Donos da Noite durante os rituais de quimbanda, o que garantia cobertura de mídia tanto para os alabês como para os terreiros contratantes.

Em um dos vídeos publicados no canal oficial dos Mestres da Magia no Youtube ${ }^{26}$, Étto Mendes e Thiago Silva agradecem a amigos e parceiros e anunciam, um ano e dois meses após a formação da equipe, o lançamento do seu primeiro $\mathrm{CD}$ :

Boa noite rapaziada do Facebook, rapaziada do Youtube, os fãs dos Mestres da Magia. Eu, Thiago Silva, e Étto Mendes estamos aqui pra agradecer vocês por este um ano e dois meses que vocês vêm acompanhando o trabalho dos Mestres da Magia. Estamos aqui pra dar uma boa notícia a todos os nossos fãs e a todas as pessoas religiosas que gostam e curtem um trabalho bem acabado, um trabalho de qualidade. $\mathrm{O}$ CD dos Mestres da Magia está pronto e começa a ser comercializado a partir do dia 5 de agosto de 2013. Gostaria de pedir encarecidamente para que náo comprem o nosso $\mathrm{CD}$ pirateado porque a continuação do segundo CD dos Mestres da Magia depende da tiragem do primeiro. Vou pedir aos nossos amigos que não apoiem, que não comprem CD pirata, ajudem o artista. Gostaria de dizer que a trajetória dos Mestres da Magia só aconteceu porque vocês todos, os nossos făs, nos deram o apoio que a gente precisou nesse um ano e dois meses.

${ }^{26}$ Publicado em agosto de 2013. Disponível em: <https://www.youtube.com/ watch? $\mathrm{v}=7 \mathrm{wCf}-$ Oetd $50 \& \mathrm{t}=94 \mathrm{~s}>$.

Debates do NER, Porto Alegre, ano i9, N. 33, P. 197-234, JAN./Jul. 20 i 8 
Ao afirmar "ajudem o artista", Thiago Silva coloca-se no campo das artisticidades, utilizando-se desse recurso ${ }^{27}$ para fazer um pedido aos făs e admiradores. Consideremos em seu discurso certas noções de criação e autoria. Aqui encontramos proximidade com a noçáo de artisticidade utilizada por Rafael Menezes Bastos (2007), em que certos elementos atuam como passe de ingresso nos universos da arte. Se, em certa dimensão, estamos falando nas influências do universo artístico, devemos considerar as diversas formas pelas quais a religiosidade afro-brasileira imprime novos contornos a essa artisticidade. Uma dessas contribuiçóes é a forma como se atribui artisticidade aos pontos gravados (e também a outros elementos da artisticidade afro-brasileira), nos levando a considerar a própria sugestáo e criação de maneiras de mediaçáo com as entidades espirituais (registradas nos CDs Luz para as Almas, por exemplo) como atributos do que é considerado um objeto de arte ou uma criação artística.

Um segundo fator que muito contribuiu para a popularidade do $L u z$ para as Almas foi a composição de pontos autorais, escritos pelos alabês e pelo produtor Felipe Paiva. Os pontos logo ficaram famosos não só entre os quimbandeiros de Porto Alegre e regiáo metropolitana, mas também entre os exus, que queriam dançar e realizar seus trabalhos mágicos ao som dos pontos que ganharam popularidade nas mãos e na voz dos dois alabês. Tal como foi explorado por Marc Gidal (2009; 2013), a produção, disseminação e performances relacionadas aos pontos de exu reforçam e evidenciam o poder desses espíritos, muitas vezes os conferindo a possibilidade de evolução espiritual. Mas a popularidade dos pontos também pode somar-se à artisticidade de seus compositores, possibilitando que pensemos no ritual de quimbanda como momento de junção das performances dos alabês artistas e dos exus, em um processos de troca de prestígio e de dádivas espirituais.

${ }^{27}$ Lembremos que, a partir dos anos 2000, a expressão “ajudem o artista” tornou-se comumente utilizada por diversos artistas que pretendiam salvaguardar suas obras a partir do combate à pirataria.

Debates do NER, Porto Alegre, ano I9, N. 33, P. I97-234, JAN./JUl. 20 I 8 
O CD Luz para as Almas é composto por 24 faixas (24 pontos) e está ordenado segundo linhagens de exus comumente cultuadas nos terreiros gaúchos. A proposta da divisão de linhagens não é uma novidade nas produçôes fonográficas do Rio Grande do Sul, mas nos possibilita compreender de que maneira certas práticas de mediação são sugeridas após o lançamento de um CD de quimbanda. Tal como explicou Étto Mendes, o CD Luz para as Almas possui passagens entre as seguintes linhas: cruzeiro, cruzeiro de alma, cemitério (calunga pequena), cruzeiro de mato, povo do mato e praia $^{28}$. Podemos pensar inicialmente sobre o trabalho conjunto desses pontos, sugerindo formas possíveis de organização ritual, de ordenação e passagem entre linhagens, de passagens entre universos espirituais de atuação. Étto afirma: "Essa curimba [a forma como se configura a passagem entre linhas no $\mathrm{CD}$ ] é a curimba da minha casa" ${ }^{29}$. O alabê refere-se ao ritual como é praticado na casa de máe Larissa, terreiro situado a poucos metros de sua casa e ao qual se considera filiado. $\mathrm{O}$ alabê também afirma que, em outros terreiros, outros pontos e maneiras de executar passagens entre linhagens podem ser postos em prática, sendo o $\mathrm{CD}$ em questão também a extensão de um terreiro específico, de suas práticas e maneiras de organização ritual.

Mas esses pontos também podem ser pensados em sua individualidade. Após o lançamento do $\mathrm{CD}$, muitos quimbandeiros separam os pontos em arquivos distintos de $\mathrm{MP} 3$, sendo possível compartilhá-los pelo WhatsApp, Facebook e outras mídias. Nesse momento, as passagens entre linhagens são desfeitas, sendo possível utilizar cada ponto de formas diversas, inclusive os adaptando a novas situaçóes e novas ordenaçôes entre linhagens. Também devemos considerar a relação entre o quimbandeiro e o seu exu, ou seja, a entidade com quem guarda fortes relaçóes espirituais. Tais relaçóes se expressam

${ }^{28}$ Para seu último DVD (É nessa gira que eu vou, 2017), gravado em estúdio, Étto Mendes escolheu 128 pontos, distribuídos de acordo com a mesma sequência de linhas do CD Luz para as Almas, porém com o acréscimo da linha do cruzeiro de lomba e lomba logo após a linha do cemitério (calunga pequena).

${ }^{29}$ Entrevista realizada em outubro de 2016. 
pela maior importância que é dada a certos pontos em detrimento de outros, sendo os CDs uma nova oportunidade de enriquecer o repertório pessoal de pontos. Para os alabês, por sua vez, os pontos entram para seu repertório pessoal, contribuindo com sua artisticidade e poder mágico-religioso. Além disso, tornam-se meios pelos quais podem homenagear seus guias espirituais $\mathrm{e}$ prestar-lhes culto tanto quanto no acendimento de uma vela ou na realização de um sacrifício. Aqui a importância do processo de gravação, do ritual do estúdio, adquire novos contornos de mediaçáo: o processo de estúdio como uma oferenda. Para os exus, esses pontos também podem ser um incremento em seu repertório, fornecendo novas formas de vir a terra e de serem convocados, de juntar sua performance à dos demais participantes do ritual.

Dito isso, passemos ao ritual, uma das dimensōes do ao vivo. Após a dissolução dos Mestres da Magia, cada alabê seguiu sua carreira solo, tentando consolidar sua própria identidade artística. Étto Mendes, por exemplo, passou a ter uma nova logomarca, impressa em seu tambor, camisetas, em capas de CD e DVD, banners de eventos. Também buscou consolidar um novo estilo de vestimenta, afastando-se da imagem construída nos Mestres da Magia e passando a utilizar um chapéu branco e um sapato branco, ambos presentes nas gravaçôes de seu DVD (gravado ao vivo em estúdio) e em suas performances ao vivo nos terreiros. 
Figura 2

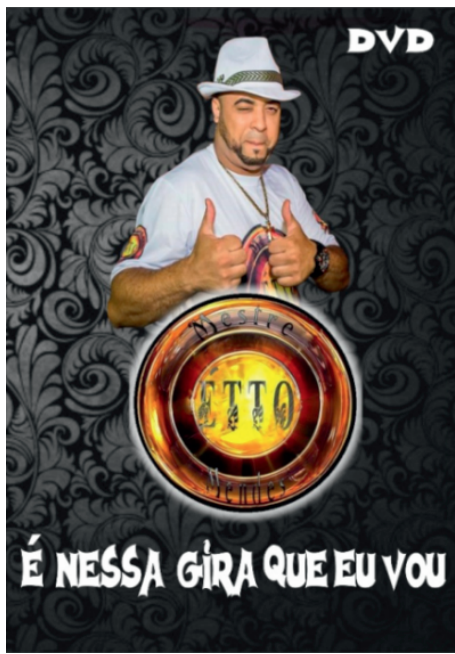

Arte da capa: Marcelo Brandão (2016).
Figura 3

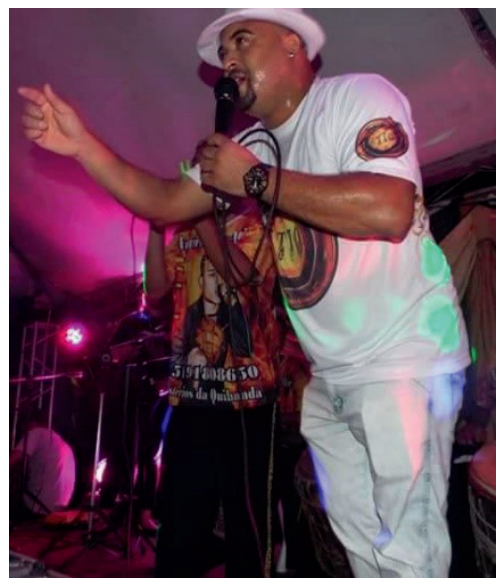

Fonte: Redes sociais alabê Étto Mendes (2016).

Além do CD Luz para as Almas (2013) e do DVD É nessa gira que eu vou (2017), Étto gravou o CD de nação Cabinda: o canto dos Orixás (2015) e participou do CD Roda de Alabês Vol. I (2016), produzido pela Donos da Noite. Esses trabalhos contribuíram para a popularidade de seus pontos e de sua identidade. Conhecido como alabê romântico por preferir compor e cantar pontos que falem sobre questóes amorosas relacionadas ao universo dos exus, bem como por evitar a execução de pontos que contenham letras consideradas pelo alabê como "pesadas", Étto é sempre convidado a cantar seus maiores sucessos durante as curimbas de exu. Médiuns e exus pedem seus pontos, pedem para juntar suas performances à performance do alabê e suas composições, suas estéticas e seu carisma.

Certa vez, pude acompanhá-lo em um de seus toques pela cidade de Porto Alegre, uma semana após a finalização do processo de gravação do seu primeiro DVD, É nessa gira que eu vou. Alguns minutos após o início do ritual, dois fatos logo chamaram atenção: primeiro, os pedidos de pontos 
(feitos pelos participantes do ritual), sobretudo os pontos lançados no CD Luz para as Almas, tais como "Vingança de Zé Pilintra" ${ }^{30}$ e "Minha vida sofrida"; segundo, a ordem dos pontos e diversos aspectos da performance do alabê, tais como a forma de pronunciar certas palavras, maneiras de "brincar" com as melodias, estratégias de condução do ritual e de presença de palco. Como afirma o alabê, alguns dos aspectos de sua performance e interação com os participantes do ritual sáo inspirados em cantores de pagode, tais como o cantor Belo, uma de suas principais influências. Alguns eram comuns aos processos de gravação que presenciei nos dias anteriores, no ambiente de estúdio. Após a curimba, comentei sobre essas questôes. Étto afirmou que a ordem dos pontos, bem como os diversos aspectos de sua performance, tinha como objetivo já apresentar ao público o próximo trabalho que estava por vir (DVD) e também fazer referência ao Luz para as Almas. Nesse sentido, as duas mídias atuavam como modelo para o ritual, trabalhando juntamente com o próprio ritual (igualmente considerado como mídia) para consolidar diversos aspectos da artisticidade do alabê.

A ritualização de estéticas e performances presentes no CD e DVD, somada à artisticidade construída a partir da cobertura de mídia e de outros recursos, evidencia a primeira dimensão do ao vivo. Como afirma Étto Mendes, referindo-se ao ritual de quimbanda: "Hoje em dia tá mais assim, é um show" ${ }^{\prime 3}$. Devemos considerar que o estabelecimento de relaçóes entre o ritual e a apresentaçáo ao vivo, tal como no caso em questão, só adquire sentido se levarmos em conta os arranjos que envolvem o gravado (ou o que se convencionou midiatizado) e o ao vivo na sociedade contemporânea e no mercado musical e artístico.

${ }^{30}$ Em decorrência da popularidade, o ponto "Vingança do Zé Pilintra" foi regravado em formato de videoclipe, no DVD É nessa gira que eu vou.

${ }^{31}$ Entrevista realizada em outubro de 2016. Em nosso diálogo, Étto comentava sobre a necessidade de interação do alabê com a câmera durante as filmagens dos rituais. 
No contexto da indústria musical contemporânea, diversos são os debates sobre a relação entre música ao vivo e música gravada ou midiatizada ${ }^{32} \mathrm{e}$, tal como Auslander (2008, p. 8) defende, "the relationship between live and mediatized forms and the meaning of liveness is understood as the historical and contingent rather than determined by immutable diferences". $\mathrm{O}$ ao vivo e o gravado, portanto, parecem orbitar de forma diferenciada nos diversos contextos em que há a possibilidade de realização do registro fonográfico (acrescenta-se as lives e vídeos no Youtube, as transmissóes ao vivo pelo Facebook, entre outros recursos), tornando-se um importante instrumento analítico. Juliana Braz Dias (2014), ao debruçar-se sobre um caso de sucesso do mercado fonográfico cabo-verdiano, sugere que, se queremos investigar a interface entra a música gravada e a música executada ao vivo, é preciso explorar não apenas o contraste entre elas, mas também como alimentam uma à outra. Passemos, portanto, a outras duas dimensóes do ao vivo, presentes no processo de gravaçáo dos CDs.

Outro alabê de grande prestígio e intensa atuação junto às novas mídias é Vagner D’Agandjú. Vagner é alabê há mais de trinta anos, exercendo a função tanto em rituais de quimbanda como em rituais de batuque e umbanda. Entre os elementos que marcam sua identidade como alabê (e também sua artisticidade), Vagner utiliza uma estécie de slogan que se repete em diversas de suas atividades: a expressão "de Lei". Vários de seus trabalhos contam com a mesma estrutura de título, bem como com a mesma logo criada pelo próprio alabê. Neste movimento, a expressão "de Lei” pode ser encontrada em camisetas, em títulos de CD, em banners colocados em eventos e festas em terreiros, fotos no Facebook, cartóes de divulgação, títulos de vídeos no Youtube, entre outros espaços. Também podemos citar o nome da equipe de alabês (foto seguinte) formada por Vagner e seus assistentes (amigos e alunos), a Equipe Balanço de Lei.

32 Ver Herschmann (2010), Auslander (2008), Emmerson (1994), Arango (2012). 
Figura 4

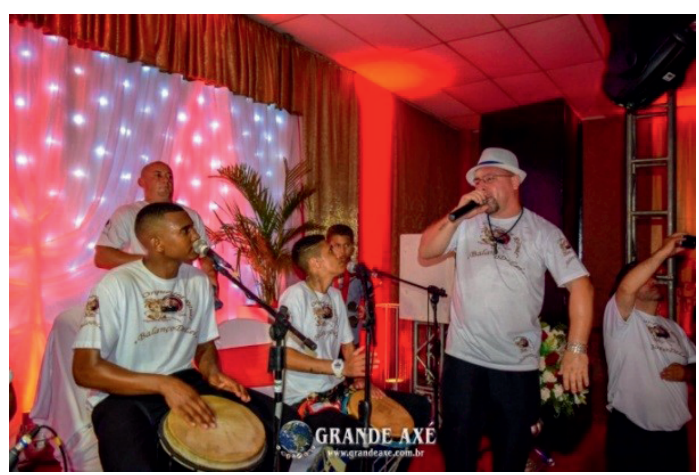

Fonte: Grande Axé (2016).

Por diversas vezes, acompanhando o alabê em seus toques em rituais de quimbanda, pude presenciar demonstraçóes da importância que é dada à "presença de palco". Por exemplo, ao final de um ritual, fomos fazer a última refeição do dia em uma loja de conveniências de um posto de gasolina. Enquanto aguardávamos outros alabês, Vagner pegou seu smartphone na intenção de me mostrar alguns vídeos que foram gravados durante rituais conduzidos por ele e sua equipe. $\mathrm{O}$ alabê logo começou a fazer comentários sobre seus assistentes, classificando-os segundo certos níveis de "presença de palco”. Em um dos vídeos, Vagner circulava o microfone entre seus amigos, possibilitando que cada um deles cantasse um ponto enquanto os outros tocavam os agês e os tambores. Segundo o alabê, alguns de seus assistentes possuíam mais presença de palco, enquanto que outros, menos experientes, ainda precisavam aprimorar sua interação com o público e com a câmera, a desenvoltura com o microfone, a condução da curimba. Essas são algumas das características de uma boa presença de palco e que devem ser postas em prática durante os rituais, o que, em certos contextos, também pode ser chamado de ao vivo.

Vagner, assim como Étto, também possui CDs considerados ao vivo, tais como o CD Kimbandasso de Lei-Ao vivo (2016), o Cânticos e Ritmos 
Ciganos-Ao vivo (2017) e o CD Roda de Alabês (2016) ${ }^{33}$. O que esses agentes consideram ser um $\mathrm{CD}$ ao vivo? Há pelo menos duas dimensóes. Primeiro, o CD gravado durante a curimba, tal como no caso do CD Cânticos e Ritmos Ciganos-Ao vivo. Nesses casos, um estúdio improvisado é montado dentro do terreiro e visa o registro do ritual. Segundo, o CD é gravado ao vivo em estúdio. Ambos os tipos de ao vivo devem possuir os elementos necessários a uma boa presença de palco, principalmente os aspectos performáticos perceptíveis para uma mídia que, apesar de limitada ao recurso auditivo, pode sugerir imagens ao ouvinte.

Com relação a esta última dimensão do ao vivo, o $\mathrm{CD}$ pode ser assim considerado quando, em estúdio, todos os músicos ocupam simultaneamente o mesmo espaço de gravação. Por exemplo, no primeiro dia de gravação do CD É nessa gira que eu vou (2016) ${ }^{34}$, do alabê Étto Mendes, Felipe Paiva dirige-se aos músicos presentes:

Seguinte, a gente tem nove microfones de capitaçáo dentro de um espaço de trinta metros quadrados, qualquer coisa vaza. A gravação é ao vivo, o que vazar, fica. Se ficar e a gente notar, tem que refazer. Então assim, é concentração. É caro, vocês sabem, a maior parte já participou de estúdio, já gravou CD. Eu conto com o profissionalismo de vocês.

Nove microfones espalhados pela sala de gravação captavam os sons produzidos. Felipe alertava para o vazamento dos sons, ou seja, mesmo que os microfones estivessem próximos a cada instrumento ou a cada músico, os sons vizinhos poderiam ser captados, resultando na impossibilidade de edição individual dos instrumentos e vozes gravados. O produtor continua, dirigindo-se ao coral:

33 O CD Roda de Alabês também contou com a participação de diversos alabês que atuam no Rio Grande do Sul, Uruguai e Argentina, entre eles, Étto Mendes.

${ }^{34}$ Apesar do processo de gravação que levou dois dias, o CD nunca foi lançado, servindo como base para a produção do DVD de mesmo nome, também gravado ao vivo.

Debates do NER, Porto Alegre, Ano i9, N. 33, P. i 97-234, Jan./Jul. 20 i 8 
Canta, solta a voz! Isso aqui é ao vivo, é como se tivesse parado numa curimba, vendo os exu dançar, o alabe tocar e vocês cantando junto. Só que vocês são bons no que fazem, vocês têm voz pra isso. Eu preciso dessa concentração de vocês, gente.

Processo semelhante aconteceu durante as gravaçóes do CD Kibandasso de Lei-Ao Vivo e do Roda de Alabês. Diferentemente do CD Luz para as Almas, gravado em canais, espaços (salas) e momentos diferentes no processo de estúdio, os CDs ao vivo (em estúdio) não possuem pontos separados por faixas. Geralmente são postas longas faixas contendo vários pontos, sendo a mudança dos toques de tambor ${ }^{35}$ ou a mudança de linhagens de exu os principais segmentadores das faixas registradas no fonograma final. Trata-se de um recurso inevitável uma vez que o processo simula "como se tivesse parado numa curimba, vendo os exu dançar". A ausência de pausas constantes entre os pontos (para recomeçar uma nova etapa de gravação) possibilita um clima de descontração, empolgação e continuidade dentro do estúdio, típico de uma curimba. Aqui o objetivo é se aproximar ao máximo da vivência do terreiro, porém com a possibilidade de registrar certas estéticas, também contribuindo com a artisticidade dos envolvidos. Esse, portanto, passa a ser um recurso de gravação atrativo, justamente por sua capacidade de sugerir e divulgar estéticas e identidades artísticas do ao vivo, passíveis de serem postas em prática nos rituais de terreiro. Aqui retomo a frase do alabê Étto Mendes: "ele [contratante] quer aquilo que ele ouviu no CD”. Dessa forma, a performance registrada no $\mathrm{CD}$ pode voltar ao terreiro, náo mais tendo este como único modelo performático, mas criando e acrescentando ao ritual, consolidando artisticidades.

35 Padrão rítmico. 


\section{CONSIDERAÇÕES FINAIS}

Busquei afirmar que o processo de profissionalização e construção de identidades artísticas dos alabês gaúchos vem possibilitando que o espaço do terreiro seja o ambiente de reafirmação dessas artisticidades. Estas, por sua vez, recebem fortes influências do mercado musical e artístico, promovendo proximidades entre o pagodô $\hat{o}^{36}$ e o palco, entre o ritual e a apresentação ao vivo, entre a condução ritual e a presença de palco. Porém, essas aproximaçóes ocorrem a partir de diversas reformulaçóes, tais como no processo de atribuição de artisticidade (diz-se "isto é arte") ao processo criativo de estéticas e performances de mediação com os exus. Enfim, criar novas formas de culto e incorporação de exus, por exemplo, muitas vezes inspiradas em modelos advindos do universo musical não religioso, pode ser considerado arte.

Náo por acaso, portanto, torna-se cada vez mais comum o uso de jogos de luz, equipamentos de som e a substituição dos antigos pagodôs por plataformas mais amplas. Nesse percurso, a artisticidade, agora capaz de conferir poder e prestígio mágico-religiosos, deixa de ser atributo exclusivo dos alabês e passa a estender-se à performance dos exus, médiuns e demais participantes de um ritual de quimbanda. Conhecer bem as pancadas no tambor e as letras das rezas e pontos, conhecer fundamentos religiosos ou ter sido aprendiz de tamboreiros respeitados não são mais os únicos atributos que conferem prestígio a esses alabês. Também é preciso possuir fẫs, logomarcas, cobertura de mídia, presença de palco, CDs e DVDs, videoclipes, atributos da nova artisticidade afro-gaúcha. Nesse sentido, a artisticidade torna-se também uma alternativa de obtenção de prestígio aos alabês mais novos ou que possuem influências fragmentadas, ou seja, que não se consideram (ou não possuem legitimidade para se afirmarem como) discípulos, aprendizes ou "da linhagem de" antigos tamboreiros prestigiados no campo afrorreligioso.

${ }^{36}$ Espécie de arquibancada feita de madeira destinada aos alabês, muito comum nos terreiros gaúchos. 
É preciso ressaltar que as demais modalidades rituais, umbanda e batuque, se relacionam de formas diferenciadas com a artisticidade e com a produção fonográfica, exigindo que levemos em consideração também os diferentes regimes de afinidade entre as divindades (entidades e orixás) e as novas mídias eletrônicas e digitais. Longe de ter ampla aceitação no meio afrorreligioso, a artisticidade é comumente enquadrada por diversos religiosos como parte do processo de espetacularização da religiosidade afro-brasileira, também bastante relacionada aos exus. Lado a lado com a espetacularizaçáo, há o desconforto gerado pelo cruzamento, ou seja, a proximidade performática e ritualística entre orixás e exus que, para muitos religiosos, gera perdas no poder mágico ${ }^{37}$. Vagner D’Agandjú, sobre a influência dos exus nas outras modalidades rituais, comenta que "o exu tira a máo do alabê de naçáo (batuque)". Por esse motivo, a artisticidade, que encontra maior expressividade junto a estes espíritos é, em alguns casos, temida pela possibilidade de gerar perdas energéticas em outras modalidades rituais.

Em uma das diversas expressóes da artisticidade apresentadas neste trabalho, o ao vivo e o gravado ganham destaque, reorganizando o fazer mágico-religioso na quimbanda. Apresentei três dimensões: primeiro, o ao vivo no terreiro; segundo, o ao vivo gravado no terreiro; e, por fim, o ao vivo no estúdio. Nesses novos arranjos, o ao vivo encontra sua razão de ser em complemento ao gravado, estendendo a experiência mágico-religiosa para além desses dois universos. $\mathrm{O} C D$, portanto, contribui com a consolidação, legitimação e sugestão de que certas estéticas produzem mediação entre pessoas entre si e entre estas e as entidades. Um exemplo disso é o próprio surgimento da modalidade ao vivo em complemento ao gravado ou ainda quando diversos alabês, influenciados pelas estéticas propostas no Luz para as Almas, passaram a usar terno durante a performance nos rituais de quimbanda.

${ }^{37}$ Ver Braga (2013) e Gidal (2013). 
Como lembra Philip Auslander (2008, p. 29) $)^{38}$, uma das estratégias da indústria cultural é a diversificação da produção musical em múltiplos objetos de consumo, em especial as variaçóes do ao vivo, o que o autor chama de projeto: gravação de estúdio, o making of da gravação, o show ao vivo, a o DVD do show, o álbum ao vivo, o videoclipe gravado ao vivo, entre outros. Influenciados por esses arranjos ${ }^{39}$, diversos alabês vêm produzindo seus próprios projetos, expandindo a artisticidade para além da performance do terreiro. Nesse processo, a chamada "cobertura de mídia" afro-brasileira explora a quebra de linearidades e submissões unidirecionais entre o ritual e o gravado, possibilitando não apenas a fragmentação da experiência de mediação, mas produzindo novas modalidades dessa experiência a partir da artisticidade estendida. Sendo a musicalidade um elemento de grande importância nas religiôes afro-brasileiras, e somada à posição de destaque possuída pelos alabês na condução ritual, a própria artisticidade ganha sua materialidade, tornando-se um importante recurso de mediação e entretenimento.

\section{REFERÊNCIAS}

AMARAL, Rita; DA SILVA, Vagner Gonçalves. Foi conta para todo canto: as religióes afro-brasileiras nas letras do repertório musical popular brasileiro. Afro-Ásia, Salvador, n. 34, p. 189-235, 2017.

${ }^{38}$ Em uma de suas proposiçóes, Auslander (2008) tenta mostrar como a performance mediatizada se tornou, em diversos contextos, a principal fornecedora dos modelos para as execuçóes ao vivo.

39 No que diz respeito à produção de "projetos", não pretendo alinhar as motivaçóes essencialmente lucrativas da indústria fonográfica às motivações dos alabês. O certo é que esses agentes, pessoas e exus, exploram as possibilidades de diversificação da experiência espiritual oferecidas pela artisticidade e pelas novas mídias. 
ARANGO, Julián Jaramillo. Imediaticidade como modelo musical: remediando a noção de ao vivo. Seminário Música Ciência Tecnologia, Săo Paulo, v. 1, n. 4, p. 309-315, 2012.

AUSLANDER, Philip. Liveness: Performance in a mediatized culture. Londres: Routledge, 2008.

BAKKE, Rachel Rua Baptista. Tem orixá no samba: Clara Nunes e a presença do candomblé e da umbanda na música popular brasileira. Religiāo \& Sociedade, Rio de Janeiro, v. 27, n. 2, p. 85-113, 2007.

BENJAMIN, Walter. A obra de arte na época de suas técnicas de reproduçấo. In: GRÜNEWALD, José Lino. A idéia do cinema. Rio de Janeiro: Civilização Brasileira, 1969. p. 9-35.

BONFIM, Evandro de Sousa. "O povo católico também tem axé": a estética pop brasileira e a inculturação carismática. Debates do NER, Porto Alegre, v. 2, n. 28, p. 37-68, 2015.

BRAGA, Reginaldo Gil. Batuque Jêje-Ijexá em Porto Alegre: a música no culto aos orixás. Porto Alegre: Fumproarte, 1998.

- Tamboreiros de Nação: música e modernidade religiosa no extremo sul do Brasil. Porto Alegre: Editora da UFRGS, 2013.

CARRANZA, Brenda. Catolicismo midiático. São Paulo: Ideias \& Letras, 2011.

CORRÊA, Norton Figueiredo. O Batuque do Rio Grande do Sul. Porto Alegre: Editora da UFRGS, 2006.

DIAS, Juliana Braz. Música e experiência na era da reprodução digital. Anuário Antropológico, Brasília, DF, n. 1, p. 219-240, 2014.

EMMERSON, Simon. 'Live' versus 'real-time'. Contemporary Music Review, v. 10, n. 2, p. 95-101, 1994.

FORBES, Bruce David; MAHAN, Jeffrey H. Religion and popular culture in America. 3. ed. Berkeley: University of California Press, 2017. 
GIDAL, Marc Meistrich. Pomba Gira as Alabê in the Quimbanda: Ritual Change, Musical Innovation, and Challenging Social Hierarchies in Southern Brazil. In: CONGRESS OF LATIN AMERICAN STUDIES ASSOCIATION, 28., 2009, Rio de Janeiro. Anais... Rio de Janeiro: LASA, 2009.

. Musical and Spiritual Innovation, Participation and Control in Brazil's Umbanda and Quimbanda Religions. Ethnomusicology Forum, v. 22, n. 2, p. 232-253, 2013.

HERSCHMANN, Micael (Ed.). Nas bordas e fora do mainstream musical: novas tendências da música independente no início do século XXI. São Paulo: Estação das Letras e Cores; FAPERJ, 2011.

- Revalorização da música ao vivo e reestruturação da indústria da música. In: GUERRINI JR., Irineu; VICENTE, Eduardo (Ed.). Na trilha do disco: relatos sobre a indústria fonográfica no Brasil. Rio de Janeiro: E-Papers, 2010. p. 165-180.

HIRSCHKIND, Charles. The Ethical Saundscape: cassette sermons and Islamic counterpublics. Nova York: Columbia University Press, 2006.

HOWARD, Jay; STRECK, John. The splintered art world of Contemporary Christian Music. Popular Music, v. 15, n. 1, p. 37-53, 1996.

- Apostles of rock: the splintered world of contemporary Christian music. Lexington: University Press of Kentucky, 2015.

JUNGBLUT, Airton Luiz. A salvação pelo Rock: sobre a "cena underground" dos jovens evangélicos no Brasil. Religião \& Sociedade, Rio de Janeiro, v. 27, n. 2, p. 144-162, 2007.

KOPYTOFF, Igor. A biografia cultural das coisas: a mercantilização como processo. In: APPADURAI, Arjun. A Vida Social das Coisas: as mercadorias sob uma perspectiva cultural. Niterói: Eduff, 2009. p. 89-121.

LYNCH, Gordon (Ed.). Between sacred and profane: researching religion and popular culture. Londres: I.B. Tauris, 2007. 
LYDEN, John C.; MAZUR, Eric Michael (Ed.). The Routledge Companion to Religion and Popular Culture. Londres: Routledge, 2015.

MARCHI, Leonardo de. Inovação e institucionalização na indústria fonográfica brasileira: um estudo de caso das estratégias de negócio de músicos autônomos no entorno digital. Revista Eptic, Sergipe, v. 14, n. 2, 2012.

MAZUR, Eric Michael; MCCARTHY, Kate (Ed.). God in the details: american religion in popular culture. Londres: Psychology Press, 2001.

MENEZES BASTOS, Rafael José de. Música nas sociedades indígenas das terras baixas da América do Sul: estado da arte. Mana, Rio de Janeiro, v. 13, n. 2, p. 293-316, 2007.

MEYER, Birgit. Mediation and immediacy: sensational forms, semiotic ideologies and the question of the medium. Social Anthropology, v. 19 n.1, p. 23-39, 2011.

MOURA, Roberto. Tia Ciata e a Pequena África no Rio de Janeiro. Rio de Janeiro: Funarte, 1983.

ORO, Ari Pedro. As religiōes afro-riograndenses na visão de dez agentes religiosos que já partiram. Revista Pós Ciências Sociais, São Luís, v. 11, n. 21, 2014.

. As religiōes afro-brasileiras do rio grande do sul. Debates do NER, Porto Alegre, ano 9, n. 13, p. 9-23, jan./jun. 2008.

. O atual campo afro-religioso gaúcho. Civitas: Revista de Ciências Sociais, Porto Alegre, v. 12, n. 3, 2012.

PEREIRA, Edmundo. Notas sobre representaçáo fonográfica: ritual de gravação e tradição musical. In: FILHO, Manuel Lima; ABREU, Regina; ATHIAS, Renato (Org.). Museus e atores sociais: perspectivas antropológicas. Recife: Editora UFPE, 2016. p. 215-243. 
PEREIRA, Edmundo; PACHECO, Gustavo. Orixás em estúdio: representações fonográficas no Candomblé. In: REUNIÃO BRASILEIRA DE ANTROPOLOGIA, 24., 2004, Recife. Anais... Recife: ABA, 2004.

ROMANOWSKI, William. Evangelicals and popular music: the contemporary Christian music industry. In: FORBES, Bruce David; MAHAN, Jeffrey. Religion and popular culture in America. Berkeley: University of California Press, 2005. p. 103-124.

ROSAS, Nina. Religião, mídia e produção fonográfica: o Diante do Trono e as disputas com a Igreja Universal. Religião \& Sociedade, Rio de Janeiro, v. 33, n. 1, p. 167-194, 2013.

SANDRONI, Carlos. Feitiço Decente: Transformações do samba no Rio de Janeiro (1917-1933). Rio de Janeiro: Editora Zahar; Editora UFRJ, 2001.

SERGL, Marcos Júlio; VICENTE, Eduardo. A Música Católica no País: a atuação da Gravadora Paulus. CONGRESSO BRASILEIRO DE CIÊNCIAS DA COMUNICAÇÃO, 31., 2008, Natal. Anais... Natal: Intercom, 2008. SOUZA, André Ricardo de. Igreja in concert: padres cantores, mídia e marketing. São Paulo: Annablume; FAPESP, 2005.

SOUZA, Licia Oliveira. Curimbas em Rendes: a música umbandista e as mediaçóes além do terreiro. 2016. Dissertação (Mestrado em Cultura e Territorialidades)-PPGCT/UFF, Universidade Federal Fluminense, Rio de Janeiro, 2016.

VASCONCELOS, Jorge Luiz. Dos terreiros para o estúdio: música, tradiçôes e contextos. [s.1.]: [s.n.], [2011]. Disponível em: <http://academia. edu/3544180/dos_terreiros_para_o_estudio_musica_tradicoes_e_contextos $>$. VICENTE, Eduardo. Música e disco no Brasil: a trajetória da indústria nas décadas de 80 e 90. 2002. Tese (Doutorado em Comunicação Social)-Escola de Comunicação e Artes da USP, Universidade de São Paulo, São Paulo, 2002. 
- A vez dos independentes (?): um olhar sobre a produção musical independente do país. Revista E-Compós, Brasília, DF, v. 7, p. 1-19, dez. 2006.

Recebido em: 08/11/2017 Aprovado em: 17/05/2018 